\title{
O ensino de línguas na região de fronteira: processos de subjetivação do aluno imigrante
}

Lourdes Serafim da Silva ${ }^{a}$

Joelma Aparecida Bressanin ${ }^{b}$

\begin{abstract}
Resumo
Este estudo se inscreve no âmbito da História das Ideias Linguísticas, articulada à Análise de Discurso de linha materialista, com o objetivo de compreender a constituição dos sujeitos e das línguas, por meio de traços de memória da/na língua manifestados em situações de ensino-aprendizado. Lançamos um olhar para as políticas de línguas, na medida em que recortamos a questão do nacional enquanto uma questão de Estado e pensamos na sua articulação com o ensino. Observamos que o embate com outra(s) lingua(s) deixa nos sujeitos marcas da subjetividade $e$, nas linguas, marcas da memória que os constituem.
\end{abstract}

Palavras-chave: Ensino de língua. Fronteira. Memória. Subjetivação. Políticas Públicas.

aUniversidade do Estado de Mato Grosso, professora efetiva da educação básica do Estado de Mato Grosso. E-mail: serafimlourdes@hotmail.com

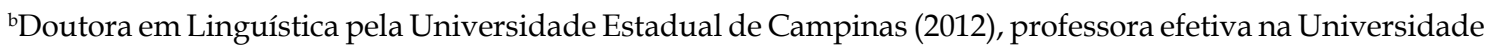
do Estado de Mato Grosso. E-mail: joelmaab@hotmail.com 


\section{Considerações iniciais}

Este trabalho resulta de uma pesquisa que desenvolvemos no Mestrado, em que analisamos a relação entre sujeitos e línguas no espaço escolar de fronteira com alunos imigrantes na Escola Estadual 13 de Maio, localizada no município de Porto Esperidião, no Estado de Mato Grosso.

Porto Esperidião faz fronteira com a Bolívia e, na maioria das vezes, as relações se dão nos dois lados da fronteira num um ir e vir sem barreiras. Entre os obstáculos que se impõem nessa região, estão questões relacionadas às línguas, pois a Bolívia, assim como a maioria dos países fronteiriços com o Brasil, por sua história de colonização espanhola, tem o espanhol institucionalizado como língua nacional, enquanto no Brasil, colonizado pelos portugueses, a língua nacional é a língua portuguesa.

A institucionalização das línguas nacionais resultou num processo de apagamento das outras línguas praticadas pelos falantes na medida em que a língua do colonizador se sobrepôs à do colonizado. Desse modo, conforme Guimarães (s/d) as relações entre as línguas, no Brasil, são relações históricas e políticas. Nessa direção, investigamos, pelo viés discursivo, as políticas públicas no que se refere ao ensino-aprendizagem de línguas para alunos imigrantes na região de fronteira e o modo como as políticas linguísticas atuam nesse processo.

Por habitar a região de fronteira, muitos alunos bolivianos imigram para o município de Porto Esperidião e adentram um novo espaço de enunciação, em que uma nova língua se faz presente: a língua portuguesa, falada e ensinada nas escolas brasileiras, numa relação de línguas marcadas pelo político. Guimarães define os espaços de enunciação como espaços políticos, pois são:

espaços de funcionamento de línguas, que se dividem, redividem, se misturam, desfazem, transformam por uma disputa incessante. São espaços "habitados" por falantes, ou seja, por sujeitos divididos por seus direitos ao dizer e aos modos de dizer. São espaços constituídos pela equivocidade própria do acontecimento. (GUIMARÃES, 2005, p. 18)

As escolas que se localizam em zonas de fronteiras, segundo Sturza (2014), constituem-se num campo de estudos discursivos privilegiado de diferenças culturais e políticas no 
convívio entre professores e alunos. Esse convívio, por diversas razões, nem sempre é pacífico.

Desse modo, esse trabalho analisa o processo de subjetivação do aluno imigrante no entremeio das línguas originárias e da língua nacional em espaço de enunciação localizado nos municípios de fronteira para compreender como ocorre a relação sujeito/língua nos espaços em que o Estado regula a Educação.

O corpus de análise foi constituído por meio de um questionário direcionado aos professores de Língua Portuguesa da escola pesquisada, do qual selecionamos seis sequências discursivas, e de duas atividades escritas por alunos imigrantes do ensino fundamental e médio, desenvolvidas em sala de aula entre os meses de março e maio do ano letivo de 2016.

\section{A região de fronteira como espaço discursivo}

Falar do ensino na região de fronteira supõe pensar a relação sujeito/língua constituída historicamente por uma diversidade linguística, além da diversidade que é própria da heterogeneidade das línguas. Essa relação se dá ora por identificação ora por uma relação de alteridade, pois os alunos buscam um pertencimento a outra discursividade, a língua portuguesa do Brasil. Nos modos da subjetivação "o sujeito imigrante é afetado contraditoriamente pela historicidade prévia à formulação do enunciado" (SERRANI, 1992, p. 3). Assim, ao aprender a língua outra desloca sua identidade, aproxima-se cada vez mais da língua do outro e distancia-se de sua língua, conforme Serrani $(1992$, p. 3) o sujeito é cindido, marcado pela perda.

Segundo Guimarães (2007, p. 65), as línguas, ao funcionarem dentro dos Estados, incluem a relação com seus falantes, lembrando que os espaços de enunciação nunca são homogêneos. No caso do Brasil, temos um espaço multilíngue tanto por questões de quais línguas são praticadas no território brasileiro, como das várias línguas nas diversas regiões do país.

Quando pensamos as fronteiras, refletimos sobre os aspectos históricos, sociais e linguísticos que fazem parte do processo de identificação do sujeito brasileiro e do sujeito imigrante. As fronteiras não se restringem ao espaço geográfico. 
${ }^{1} \mathrm{O}$ povo Chiquitano constitui-se por uma mistura de grupos indígenas que adentrou o território brasileiro, vindos da Bolívia, devido aos conflitos entre os jesuítas e os espanhóis no século XVII. Em Porto Esperidião, observa-se parte de seus costumes como o Curussé que é uma variação do carnavalito boliviano, e em comunidades que falam um dialeto originário do Aymara. (PME, Porto Esperidião, 2003)
São limites que se fazem e se movimentam pela constituição dos sentidos.

A região de Porto Esperidião teve seu desenvolvimento inicial marcado pela construção das linhas telegráficas pelo Marechal Cândido Mariano da Silva Rondon, o Marechal Rondon, por volta de 1906, dando origem ao povoado de Porto Salitre que mais tarde se tornou Porto Esperidião (FERREIRA, 2008). Era objetivo da expedição Rondon fazer o mapeamento geográfico e a instalação das linhas telegráficas. Os expedicionários fizeram, também, registros linguísticos elaborando listas de palavras, alguns textos e ensaios de descrição gramatical, o que contribuiu para o conhecimento das línguas indígenas brasileiras (RODRIGUES, 2004).

Nossa investigação se realiza na Escola Estadual 13 de Maio, situada no perímetro urbano de Porto Esperidião. Ela foi criada no ano de 1979 e desde 1983 funciona em prédio próprio, no centro da cidade. Atualmente, atende a alunos provenientes de uma sociedade heterogênea, formada por migrantes de várias partes do Brasil, de origem principalmente das regiões Sul e Sudeste e de povos Chiquitanos ${ }^{1}$ e imigrantes bolivianos.

Conforme descreve o Projeto Político Pedagógico (PPP) da instituição, a escola é um marco referencial do município devido ao grande índice de alunos aprovados em instituições de nível superior em várias universidades do país e atende à comunidade de uma forma geral, dando possibilidade de empregabilidade e sustentabilidade.

A escola torna-se então um lugar de referência e conta com aliados importantes tais como a internet, materiais didáticos diferenciados, contato com o rico mundo da leitura, portanto a escola está articulada a um conjunto de redes e informações que passam a ser mais um elemento vital para a produção de conhecimento. (PPP, 2016, p. 6) (grifos nossos).

Esse imaginário de escola de referência se constrói historicamente e significa dentro do ambiente escolar e fora dele, em seu entorno, legitimando as práticas que ocorrem em seu interior, conforme nos mostra Orlandi (1994, p. 57): "se se tira a história, a palavra vira imagem pura. Essa relação com a história mostra a eficácia do imaginário, capaz de determinar transformações nas relações sociais e de construir práticas".

A região de fronteira possui algumas especificidades, que a tornam particular, referentes às línguas que ocupam um 
espaço de dizer, constituído desde o processo de colonização linguística, e entram em tensão agora na escola. Muitos alunos bolivianos que se matriculam na Escola Estadual 13 de Maio tiveram alfabetização em língua espanhola, na maioria das vezes, a língua materna e nacional, e se deparam com um ensino heterogêneo, formulado em língua portuguesa, a língua nacional do Brasil.

\section{A constituição da língua nacional brasileira: memória e história}

A língua portuguesa, no início da colonização do Brasil, marcou-se por embates com as outras línguas existentes no território brasileiro e durante esse período de tensão não foi a única língua de comunicação. Segundo Pires (2009), a língua falada na Colônia passou a ser a língua Brasílica e mais tarde a língua geral. Essas línguas foram uma forma de comunicação entre os nativos e os recém-chegados portugueses, e também, entre os próprios indígenas, que, para se comunicar dentro das próprias tribos e/ou com tribos que falavam outras línguas, valeram-se da língua Brasílica. A língua Brasílica falada por toda a costa brasileira, inclusive pelos portugueses que aqui viviam, foi modificada pelo uso corrente de índios e nãoíndios, a partir da segunda metade do século XVII e passou a se chamar a língua geral (PIRES, 2009).

A substituição da língua geral pela língua portuguesa culminou com a publicação do Diretório dos Índios, documento que Sebastião José de Carvalho e Melo, posteriormente Marquês de Pombal, publicou em 1757, após a expulsão dos jesuítas. Sobre a questão das línguas, o Diretório foi significativo na implantação da língua portuguesa em detrimento da língua geral e de outras línguas faladas pelos índios.

Em seu artigo sexto, o Diretório compara o Brasil a outras nações, que chama de "nações polidas do Mundo", e que impuseram, no início da colonização, suas línguas, apagando as línguas das nações conquistadas.

Quanto ao Brasil, o texto afirma que aqui ocorreu o contrário, pois os colonizadores se preocuparam em implantar a língua que chamaram de língua geral. Essa língua foi chamada de "invenção verdadeiramente abominável, e 
diabólica", pois privava os índios de civilidade e os fazia permanecer "na rústica, e bárbara sujeição, em que até agora se conservavam". Não há nenhuma menção a um portuguêsbrasileiro, confirmando a imaginária unidade linguística que confere o caráter nacional a Portugal. (MARIANI, 2003).

Assim, o Diretório instituía o uso da língua portuguesa, para acabar com o "abuso" em que se configurava o uso da língua geral:

não consentindo por modo algum, que os Meninos, e as Meninas, que pertencerem às Escolas, e todos aqueles Índios, que forem capazes de instrução nesta matéria, usem da língua própria das suas Nações, ou da chamada geral; mas unicamente da Portuguesa, na forma, que Sua Majestade tem recomendado em repetidas ordens, que até agora se não observaram com total ruína Espiritual, e Temporal do Estado. (NAÇÃO MESTIÇA/Diretório dos Índios, Artigo VI, 2015).

Conforme estabelecia o Diretório, os meninos e meninas que fossem à escola e indígenas capazes de instrução deveriam usar "unicamente" a língua portuguesa, sob o risco de uma "total ruína Espiritual e Temporal do Estado", provocando, com isso, o silenciamento da língua geral. O Diretório dos Índios foi uma política que marcou definitivamente a mudança linguística que houve no Brasil no final do século XVIII.

A partir da segunda metade do século XVIII, a língua portuguesa se impôs no território brasileiro e silenciou as outras línguas. Depois da independência, tornou-se a língua nacional do Brasil, com características próprias que a diferencia do português de Portugal, confirmando a história de silenciamento de outros falares.

Segundo Guimarães (2007), a história sobre a língua portuguesa no Brasil, no geral, desconhece as relações políticas envolvidas na implantação do português como língua nacional brasileira. Para o autor, aceitá-la significaria entender o que está silenciado. Nesse processo, marcado por relações de força e de poder, a língua do colonizador, em geral, sobrepõese à do colonizado, silenciando outras línguas. Isso explica a hegemonia da língua portuguesa sobre as outras línguas faladas no Brasil à época da colonização e que ressoa nas atuais políticas de línguas. 
Dessa forma, a constituição da língua portuguesa falada no Brasil apresenta uma história marcada por uma política linguística opressora e impositiva, que promoveu a interdição de outras línguas e resultou na constituição de um imaginário de unidade linguística. Mariani afirma que:

A unidade linguística é um dos elementos que vai constituir a identidade nacional no lento processo de constituição histórica dos estados nacionais: uma única língua oficial a ser usada pelos cidadãos com a função de regular juridicamente as relações de vassalagem. (MARIANI, 2004, p. 51)

Observamos que a unidade linguística passa a ser constitutiva da identidade nacional no decorrer desse processo, na medida em que a afirmação do Brasil enquanto nação se dá pela imposição da língua portuguesa como língua oficial no território nacional. E o resultado desse funcionamento é o aparecimento de uma forma sujeito controlada/regulada quanto ao modo de se significar pela/na língua. Em outras palavras, o Estado impõe ao cidadão um certo modo de estar na língua, sob certas condições, com determinadas formas e não outras.

Ainda, segundo Mariani (2004), o caráter técnico na criação de políticas linguísticas resulta no silenciamento e organiza o espaço de circulação das línguas. O Diretório dos Índios delegou lugar de destaque à língua portuguesa sobre a língua geral, com a proibição desta nos espaços educativos do Brasil Colônia impondo a nacionalização do português como língua oficial no Brasil.

Nessa direção, Di Renzo afirma que

estabelecer relações entre os acontecimentos históricos que deram origem ao Estado brasileiro e à constituição de uma (sua) língua nacional nos permite não só refletir sobre o discurso da história, mas sobretudo, nos permite reinterpretar esses acontecimentos atravessados pelo discurso sobre a língua. (DI RENZO, 2005, p. 31-32)

Assim, através do estudo do modo como a língua do colonizador foi imposta para garantir presença política na Colônia, podemos entender os acontecimentos históricos que deram origem ao Brasil. Notamos que se repete a imposição da língua da mesma forma que se impõe a presença dos portugueses nas terras brasileiras. 
Vejamos, a seguir, algumas reflexões sobre o modo como as políticas públicas de ensino vêm se configurando no cenário nacional, para pensarmos a questão da política de línguas na perspectiva discursiva, ou seja, quando pensamos o ensino de línguas, pensamos em práticas sociais sendo significadas por e para sujeitos históricos e simbólicos, em suas formas de existência e de experiência no espaço político de seus sentidos (ORLANDI, 2007).

\section{A nacionalização do português do Brasil: a fronteira e o ensino de língua}

Muitos bolivianos se mudam para o Brasil, principalmente em busca de trabalho, para conseguir remuneração e qualidade de vida melhores. Segundo Silva (2006, p. 157), os imigrantes hispano-americanos têm um imaginário do Brasil como um país exuberante, o "país do futebol, do samba, de belas praias, das mulatas, das oportunidades de emprego, entre outras".

Assim, os alunos que imigram se veem frente à língua portuguesa, a língua oficial do Brasil, que é materialmente diferente da(s) língua(s) que pratica(m) em seu país, com características históricas, culturais e sociais distintas.

Entendemos que o ensino de línguas em região de fronteira é fortemente marcado por relações históricas e culturais. Essas relações constituem as línguas e os sujeitos, uma vez que sujeitos habitam esse espaço. A linguagem tem aspecto linguístico e histórico, ambos constitutivos do sujeito do discurso e dos sentidos, conforme ressalta Orlandi:

A análise do discurso trabalha com a materialidade da linguagem, considerando-a em seu duplo aspecto: o linguístico e o histórico, enquanto indissociáveis no processo de produção do sujeito do discurso e dos sentidos, que (o) significam. O que permite dizer que o sujeito é um lugar de significação historicamente constituído. (ORLANDI, 2001, p. 36-37)

Nessa direção, a linguagem enquanto prática simbólica nos leva a pensar nos processos de identificação do sujeito com a língua e com a história, pois "ao significar, o sujeito se significa" (ORLANDI, 2001, p. 22). Dessa forma, a dificuldade de o aluno imigrante aprender a outra língua se relaciona com o modo como a língua portuguesa é significada, ou seja, 
a língua portuguesa legitimada na escola é trabalhada pela norma, pela organização.

Assim, segundo Payer e Celada (2016), a aprendizagem de línguas deveria ir na direção de levar o sujeito de aprendizagem à compreensão da constituição das línguas, deveria não apenas preocupar- se em ensinar os conteúdos gramaticais, a estrutura da língua, mas também pautar-se num ensino "que se subordine à ordem, ao funcionamento da língua, e não à organização que fazemos operar como representação desse funcionamento" (PAYER; CELADA, 2016, p. 24).

Diríamos que é falando da diversidade linguística, étnica e cultural que se apaga o sujeito imigrante e todos os sujeitos (negros, índios) que constituem a nação brasileira. Colocam todas as etnias em um mesmo grupo, enquanto "povos" que produziram uma história que precisa ser contada de modo "cuidadoso por parte da escola". Em outras palavras, uma história que sempre foi narrada pelo colonizador, produzindo seus efeitos. Efeitos de uma colonização linguística, que apaga a tensão entre línguas, em detrimento de condições que valorizem as outras línguas praticadas pelos sujeitos.

Nesse sentido, observamos que há uma interdição da língua falada pelo sujeito imigrante, pois ao chegar à escola brasileira entra em contato com uma língua diversa da língua que pratica, sendo sua língua desautorizada a circular nesse espaço, como nos aponta Zoppi-Fontana:

[...] o estudo de práticas discursivas definidas por processos de identificação a partir dos quais o sujeito do discurso se constitui na sua concreta função de enunciador afetado por uma desqualificação, uma deslegitimação e, inclusive, uma interdição desse seu dizer. Posições de sujeito que se caracterizam por um esvaziamento/silenciamento da função enunciativa que afeta tanto os processos de constituição do sujeito quanto os efeitos dos enunciados aí produzidos, cujas formulações sofrem restrições de circulação. (ZOPPIFONTANA, 2003, p. 275)

As práticas discursivas do aluno imigrante e os processos de identificação com as línguas em circulação na escola brasileira passam por uma desqualificação, deslegitimação de seu dizer. As formulações feitas na língua que pratica sofrem restrições de circulação. E uma vez que há a interdição de seu dizer, há também um esvaziamento da sua função enunciativa. $\mathrm{O}$ aluno imigrante é silenciado e se silencia. 
Cabe destacar que o conhecimento linguístico que os alunos trazem está relacionado às práticas sociais que eles vivenciam fora da sala de aula, em sua língua. Esse conhecimento é interditado, quando a escola só permite que o aluno produza textos orais e escritos em língua portuguesa.

\section{A análise do corpus}

Apresentamos a análise do corpus que organizamos a partir dos discursos das professoras docentes de Língua Portuguesa na escola pesquisada e da produção escrita dos alunos imigrantes.

Entrevistamos oito professoras do ensino fundamental e ensino médio e fizemos uma seleção das entrevistas que consideramos mais relevantes para o que propomos compreender. Ressaltamos que utilizamos um questionário estruturado, cujas repostas foram digitadas tais como foram formuladas pelas professoras. Apresentamos um corpus composto por seis sequências discursivas (SD), que, como propõe Courtine (2009, p. 55), são "sequências orais ou escritas de dimensão superior à frase".

Quanto às atividades de escrita realizadas pelas professoras com seus alunos, fizemos a seleção de quinze atividades produzidas por alunos imigrantes, que recebemos nos meses de abril e de maio de 2016. Configuramos o corpus com duas produções por trazerem uma amostragem do processo de subjetivação dos alunos imigrantes que se repetem em outras produções. Dessa forma, analisamos a escrita dos alunos que compõem o nosso corpus, considerando que essa escrita se inscreve na ordem da subjetividade, na historicidade constitutiva dos discursos passíveis de interpretação.

\subsection{O processo de identificação do sujeito-professor de} Língua Portuguesa com as políticas de Estado

Para a Análise de Discurso, analisar um discurso, nesse caso, o das professoras de Língua Portuguesa, significa tomálo como objeto histórico-ideológico. Orlandi (2015, p.13) afirma que, na Análise de Discurso, "procura-se compreender a língua fazendo sentido, enquanto trabalho simbólico, parte do trabalho social geral, constitutivo do homem e da sua história". 
O processo de constituição do sujeito se dá pela interpelação do indivíduo em sujeito pela ideologia. É a ideologia que determina o que pode e deve ser dito, em uma dada formação discursiva.

Segundo Pêcheux (1995, p. 160), "as palavras, expressões, proposições mudam de sentido segundo as posições sustentadas por aqueles que as empregam". Para o autor as palavras, expressões, proposições adquirem sentido em referência às formações ideológicas que as sustentam. Assim, nos interessa analisar a posição-sujeito que as professoras ocupam e as formações discursivas nas quais inscrevem seus discursos.

Vejamos:

SD1: Bem, acredito que os alunos são bem acolhidos, a socialização dos mesmos é ótima e que tanto a direção e coordenação da Escola quanto o coletivo de professores e demais educadores se empenham para que o desenvolvimento desses alunos oriundos de outro país seja pleno. O fluxo de imigrantes para o nosso município é constante e não vejo problemas.

Nessa SD, o sujeito-professor destaca que o corpo docente da escola se empenha para o desenvolvimento social pleno do aluno imigrante. A professora fala de seu lugar social, ocupa a posição sujeito-professor ao enunciar, ou seja, seu dizer é produzido pelo imaginário, que é social e resultado de relações de poder e de relações de sentido. A imagem que se faz de um professor e os sentidos que seu dizer produz são afetados pelas relações de força, que se sustentam pelo poder do lugar social que o professor ocupa, ou seja, seu dizer se inscreve numa dada formação discursiva, que, de acordo com Pêcheux (1995), se refere àquilo que pode e deve ser dito, ou seja, o sujeito tem a ilusão do sentido único.

Há um pré-construído que retoma o modo como o brasileiro recebe o estrangeiro. Recorremos a Diniz (2008) quando aborda a imagem do brasileiro, numa posição discursiva de cordialidade pela perspectiva do estrangeiro. $\mathrm{O}$ brasileiro acolhe bem e é visto como gente boa, alegre, festiva. Instala-se aí uma contradição, outra posição discursiva da identidade brasileira, pois o brasileiro não reconhece a língua do outro.

É nessa mesma direção que outros sujeitos-professor vão dizer sobre o trabalho da instituição. 
SD2: Os alunos tem muita facilidade na interação com os demais, percebo uma ótima rotina, sendo que, não são excluídos quando se forma grupos, em apresentações da escola, ou até mesmo em atividades individuais. A escola como instituição de ensino, sempre apoia a interação desses alunos, proporcionando espaço, tempo em diversas apresentações culturais, regionais que organiza e sempre tem danças onde esses alunos são incentivados pelos professores a apresentar, e são ótimas apresentações, pois não se preocupam com o olhar dos demais. (grifo da professora)

O sujeito desse discurso enuncia na SD2 que a escola promove a participação em grupos, danças, apresentações, num trabalho que favorece a inclusão social. Percebemos que seu dizer se inscreve numa formação discursiva que leva em consideração a preocupação com a inclusão social. Podemos colocar esse dizer em relação de sentido a "uma educação humanizadora que considera a realidade do aluno, respeitando o desenvolvimento biológico e a interação social" (BRESSANIN, 2013, p. 28). Ao dizer que a instituição sempre apoia a "interação" dos alunos, o sujeito-professor se identifica com os discursos em circulação na escola, que ora recobrem, ora apagam sentidos já ditos nas políticas de ensino a esse respeito.

Nesse ambiente educativo, convivem/debatem a língua portuguesa e outras línguas maternas em suas várias formas, seja na linguagem formal ou informal, ou ainda, na mistura das línguas, quando o aluno se posiciona no entremeio na aquisição de uma nova língua (CELADA, 2008).

$\mathrm{Na}$ SD2, há uma pista da diferença no tratamento entre os alunos, que nos possibilita subentender que os imigrantes são vistos de outra maneira, pois, ao relatar que o aluno imigrante não se preocupa com "o olhar dos demais", o sujeito-professor dá a entender que, apesar de participarem das atividades, a inclusão não ocorre do mesmo modo, ou seja, os alunos bolivianos são vistos de outra forma.

Sobre o funcionamento da negação no discurso, Indursky (1997, p.213) formula o conceito no qual destaca que "a negação é um dos processos de internalização de enunciados oriundos de outros discursos, podendo indicar a existência de operações diversas, no interior do discurso em análise". Assim, nas formulações "não são excluídos quando se forma grupos" e "não se preocupam com o olhar dos demais", a professora ao 
negar reivindica, ainda que inconscientemente, as afirmações do discurso-outro, isto é, nega-se o que poderia afirmar.

A SD3 aborda o modo de tratar o aluno imigrante como um aluno brasileiro:

SD3: Até então percebi que não interferiu no processo de ensino e de inclusão trato ele com fosse um aluno nascido aqui.

O sujeito-professor, nessa SD, numa compreensível atenção dada, especialmente à língua portuguesa, a língua oficial do brasileiro, demonstra um apagamento das línguas do imigrante, pois se o aluno é "nascido aqui", ele é visto como brasileiro.

Ao considerar apenas uma língua, a língua portuguesa, para um grupo de alunos, como descrito pelo sujeito-professor, nessa SD, deixa-se de considerar a diversidade linguística dos alunos na região de fronteira. Desse modo, a língua portuguesa é colocada em posição hierárquica, à frente das demais línguas, espanhola, indígena e outras. Esse apagamento reatualiza uma política linguística opressora em relação à variedade de línguas no nosso país e à diferença entre línguas na região de fronteira.

A SD abaixo textualiza que a estrutura correta é a da língua portuguesa e novamente o aluno precisa adaptar-se à nova língua.

SD4: Nas produções de texto sempre encontro erros em relação a estrutura, ortografia etc. quando surge essa ocorrência, peço para refazer o texto e explico como seguir a estrutura correta.

Nessa SD, observamos que as línguas praticadas pelos alunos são interditadas e instala-se, então, um conflito entre a língua do imigrante e a língua nacional brasileira, resultando no "erro", que é corrigido com base na escrita da língua portuguesa.

Entendemos com Orlandi (2015) que sujeito e sentido se constituem. Nessa direção, compreendemos que a língua é constitutiva do sujeito. Payer (1999) afirma que o que faz falta na escrita falta no sujeito. Essa falta vem, a nosso ver, da diferença entre as línguas nacional e materna que deixam vestígios na escrita e na oralidade do aluno quando ele enuncia.

A SD abaixo responde ao questionamento feito sobre os cursos de formação continuada, a Sala do Educador, e/ou outras 
ações de formação ofertadas pela instituição, para o trabalho com alunos imigrantes.

SD5: Bem até hoje não tivemos capacitação, os cursos de formação continuada não são com enfoque para a clientela de alunos imigrantes por mais que tenhamos vários alunos na instituição. A sala do educador ainda não teve temáticas voltadas a esses alunos. Nem mesmo outra formação.

Para o sujeito-professor não há políticas de formação continuada que envolvam o aluno imigrante. E afirma que uma política de formação implantada é a sala do educador projeto implementado pelo Centro de Formação e Atualização dos Profissionais da Educação de Mato Grosso (CEFAPRO) que coordena as temáticas a serem discutidas na formação continuada. No entanto, também afirma que o projeto não prevê temáticas para desenvolver o trabalho pedagógico na região de fronteira. Ou seja, há cursos de formação continuada, mas não tratam de questões relativas ao ensino de línguas para imigrantes.

Apesar desse contexto, os educadores da escola pesquisada demonstram preocupação com a língua, conforme relatos como a SD6.

SD6: Não temos cursos, apenas leituras que fazemos ao longo do ano, quando percebemos a necessidade de conhecer melhor a estrutura da língua.

Nessa SD, outro sujeito-professor afirma que não há cursos de capacitação para o trabalho pedagógico com alunos imigrantes. Desse modo, não há, na unidade escolar, formação continuada para um trabalho que considere a constituição do aluno imigrante enquanto sujeito de linguagem. Notamos que a preocupação ainda permanece nas questões relativas à estrutura da língua, pois quando percebe a necessidade de conhecer melhor a estrutura da língua, o docente realiza leituras para sanar a dificuldade.

Para atender ao ensino pensado como forma de garantir a construção da identidade do aluno como sujeito do conhecimento e da(s) língua(s), a formação de professores precisa ir além do imediatismo das capacitações, ou seja, formar o professor para atuar além das competências, vistas como um meio de suprir as necessidades dos alunos. $\mathrm{O}$ professor, nessa posição sujeito, poderá levar o aluno "a ser 
capaz não só de formular como reformular e ressignificar sua relação com a língua e com a sociedade" (ORLANDI, 2014, p. 163), para que uma vez individuado pelo Estado o sujeito se signifique no processo ensino aprendizagem.

\title{
5.2. Sobre ensino de língua na escola: memória e escrita
}

Para observar os traços da língua interditada nas práticas de escrita dos alunos imigrantes selecionamos para análise as produções dos alunos em que surgem tais vestígios.

Vale ressaltar que falamos da escrita como prática discursiva, passível da exterioridade e dos efeitos de evidência, resultando num texto em que a incompletude, a memória e a historicidade significam, ou seja, conforme Schons (2011, p. 140), um texto que "não se constrói sem esse exterior".

Apresentamos, na sequência, um poema produzido por um aluno do segundo ano do ensino fundamental, na atividade solicitada pela professora por ocasião das comemorações do Dia das Mães:

\author{
Mámãe é minha raina \\ E quida de mim \\ Parece uma fada \\ E ela é muito calada \\ Gosta de cantar \\ E dansar:
}

Nesse poema, o aluno descreve o modo como identifica sua mãe: "é minha raina". A nosso ver, constrói a imagem de sua mãe de forma bastante expressiva e poética: "parece uma fada". Destaca também algumas características: "muito calada" e gosta de cantar e de dançar.

Na escrita dos versos "Mámãe é minha raina/E quida de mim", chamou-nos atenção a memória da língua do imigrante funcionando, pois, o aluno escreveu raina numa tentativa de escrever reina, rainha em espanhol, ao enunciar que sua mãe é a sua rainha.

Observamos também a acentuação da palavra mamãe (Mámãe), em que houve uma proximidade com a língua praticada pelo aluno. Pensamos que isso ocorre em razão da sonoridade da sílaba inicial da palavra. Em língua espanhola, esse som classifica-se como aberto, dessa forma, justifica-se o uso da acentuação na palavra mámãe. O aluno articula vários 
saberes linguísticos sobre acentuação para escrever a palavra em português.

Apresentamos, a seguir, um excerto de uma narrativa, na qual a aluna do segundo ano do ensino médio, ao explicar o valor das mãos, conta a história de um açougueiro que perdeu uma das mãos.

Um carniceiro, trabalhador, amava muito sua família.

Um dia qualquer, aconteceu uma tragédia, onde perdeu uma mão.

Muitos indivíduos irão desistir de viver ou isolar-se por vergonha, más este carniceiro não, e também não parou com seu serviço. Hoje em dia ele pega uma faca e a amarra na munheca, onde continua sendo carniceiro, e seguindo em frente.

Nessa narrativa, notamos uma singularidade no modo como a aluna imigrante elabora sua escrita. Utiliza, inicialmente, termos indefinidos: "um carniceiro", "um dia qualquer", "uma tragédia" e "perdeu uma mão". Porém, o aspecto linguístico está associado ao cultural e, ao definir as características do "carniceiro", ela expressa os valores, crenças e a visão de mundo por meio dos quais constrói uma imagem positiva do sujeito que é capaz de superar a tragédia, especifica "trabalhador" e "amava muito sua família". Acreditamos que o sujeito se significa na relação com o social e o cultural, ou seja, os traços de memória são instaurados ao longo da história de sua inscrição no modo de vida e na elaboração dos sentidos.

Na escrita da aluna há uma projeção significativa em relação ao convívio social: "Muitos indivíduos irão desistir de viver ou isolar-se por vergonha, más este carniceiro não". Desse modo, acreditamos que as práticas de ensino devam ser pensadas como processos de subjetivação, que atravessam o campo de uma subjetividade e que trabalham a memória discursiva, tal como propõem Celada (2008) e Celada e Payer (2016).

Quanto à memória da língua, esta irrompe no discurso por meio do emprego da palavra "carniceiro". Carnicero é uma expressão da língua espanhola, que corresponde a açougueiro em língua portuguesa. Dessa forma, no processo da aquisição da língua portuguesa, o imigrante transita no entremeio das línguas e rememora o léxico que não é da língua portuguesa. No entanto, no emprego do sufixo "ero/eiro", pode-se observar o 
processo de ditongação que ocorre no português. Encontramos, ainda, nesse recorte, um retorno à memória de língua ao empregar a palavra "mas" com acento agudo más, como é o caso da ortografia dessa palavra na língua espanhola. Esses indícios na escrita da aluna chamam atenção em relação ao uso das normas gramaticais do espanhol já apreendidas no processo de alfabetização iniciado na língua oficial de seu país.

Do ponto de vista discursivo, entendemos a língua como constitutiva do sujeito, heterogênea por formação, na dimensão da ordem, do funcionamento na história e as análises feitas nos permitem afirmar que a língua não é um instrumento inerte, mas se forma, também, pela resistência à imposição, nesse caso, a resistência dos sujeitos imigrantes ao silenciamento/ apagamento das línguas que praticam no espaço escolar, pois ao se inscrever na ordem de um saber sobre a língua, o sujeito de linguagem imprime a marca de subjetivação nos contatos da língua com a exterioridade.

\section{Considerações finais}

Notamos a diversidade das línguas presentes no ambiente pesquisado, pois a escola situa-se em um município de fronteira com a Bolívia e recebe constantemente alunos vindos do país vizinho. Nesse ambiente há situações em que as línguas parecem não fazer sentido para os sujeitos, dada a não coincidência entre as línguas que são praticadas pelos alunos brasileiros e imigrantes.

Apesar de haver um discurso de valorização do aluno enquanto sujeito de linguagem, constituído historicamente, nas políticas públicas implementadas para o ensino de língua no Brasil, ainda vemos que tais práticas ocorrem por meio da imposição de uma unidade linguística e do silenciamento/ apagamento de outras línguas. Todavia, essas práticas não significam um apagamento absoluto do outro, pois os sujeitos resistem e suas próprias línguas, mesmo silenciadas, permanecem funcionando como um lugar de memória, de modo constitutivo (PAYER, 2006).

Destacamos a importância de as atuais políticas públicas de ensino considerarem o grande número de alunos imigrantes no ensino da língua oficial nas escolas brasileiras. 
Em municípios fronteiriços com os países que têm o espanhol como língua nacional, em especial, no estado de Mato Grosso, pela sua extensa fronteira com a Bolívia, o ensino de línguas, na maioria das escolas, silencia o sujeito imigrante e a sua língua.

Destacamos também a necessidade de uma reflexão sobre o modo como as línguas são pensadas e trabalhadas nas unidades escolares, considerando que os sujeitos e as línguas se constituem. Ou seja, o ensino de línguas precisa ser pensado num processo de subjetivação dos sujeitos-alunos. Nessa direção, Celada (2002) afirma que "a língua não apenas é falada pelo sujeito; ela o constitui, intrinsecamente, como ser simbólico, e ela o 'designa'". Em outras palavras, esperamos possibilitar aos sujeitos refletir sobre o modo como as línguas atravessadas pelo político se significam nas instituições escolares em que há um batimento entre as línguas materna e nacional, especialmente nos espaços enunciativos de fronteira, em que as relações entre os sujeitos e as línguas são contraditórias, ora se aproximam ora se distanciam. E demonstram como os sujeitos são afetados pelas condições sócio-históricas da fronteira como espaço de línguas em convívio.

\section{REFERÊNCIAS}

BRESSANIN, A. O currículo no movimento das políticas de ensino de língua portuguesa: a língua que falha, falta. 2013. 89f. Dissertação (Mestrado em Linguística). Universidade do Estado de Mato Grosso, Cáceres/MT, 2013.

CELADA, M.T.; PAYER, M.O. Sobre sujeitos, língua(s), ensino. Notas para uma agenda. In: . (Org.) Subjetivação e processos de identificação: Sujeitos e línguas em práticas discursivas inflexões no ensino. Campinas, SP. Pontes Editores, 2016, p.17-41. CELADA, M.T. O que quer, o que pode uma língua? Língua estrangeira, memória discursiva, subjetividade. Letras, 37, v.18, n.2, p.145-168, 2008. Disponível em: < https://periodicos.ufsm. br/letras/article/view/11985/7399 >. Acesso em: 14 jan. 2017.

. O espanhol para o brasileiro: uma língua singularmente estrangeira. 2012. 277f. Tese (Doutorado em Linguística). Instituto de Estudos da Linguagem, Universidade Estadual de Campinas, Campinas/SP, 2002. 
COURTINE, J.J. Análise do discurso político: o discurso comunista endereçado aos cristãos. São Carlos: EdUFSCar, 2009.

DINIZ, L.R.A. Mercado de línguas: a instrumentalização brasileira do português como língua estrangeira. 2008. 201f. Dissertação (Mestrado em Linguística). Instituto de Estudos da Linguagem, Universidade Estadual de Campinas. IEL/ UNICAMP. Campinas/SP, 2008.

DI RENZO, A.M. A constituição do Estado brasileiro e a imposição do português como língua nacional: uma história em Mato Grosso. 2005. Tese (Doutorado em Linguística). Instituto de Estudos da Linguagem, Universidade Estadual de Campinas. IEL/ UNICAMP. Campinas, SP, 2005.

FERREIRA, J.C.V. Mato Grosso e seus municípios. 2008. Disponível em: < http://www.mteseusmunicipios.com.br/municipios/ porto-esperidiao/historia-de-porto-esperidiao/541 >. Acesso em: 05 jun. 2016.

GUIMARÃES, E. Política de línguas na linguística brasileira. In: ORLANDI, E. (org.). Política Linguística no Brasil. Campinas, SP: Pontes, 2007.

Semântica do acontecimento: um estudo enunciativo da designação. 2. ed. Campinas, SP: Pontes, 2005.

. Relações de línguas. In. ENCICLOPÉDIA das línguas do Brasil. Disponível em: < www.labeurb.unicamp.br/elb2/ pages/noticias/lerArtigo.lab?categoria $=12 \& i d=76>$. Acesso em: 14 jan. 2017.

INDURSKY, F. A fala dos quartéis e outras vozes. Campinas, SP: Unicamp, 1997.

MARIANI, B. Colonização linguística: línguas, política e religião (Brasil, sécs. XVI a XVIII e Estados Unidos da América, século XVIII). Campinas, SP. Pontes, 2004.

Políticas de colonização linguística. Letras, n.27, p.73-

82, 2003. Disponível em: < https://periodicos.ufsm.br/letras/ article/view/11900/7322 >. Acesso em: 11 nov. 2016.

NAÇÃO MESTIÇA. Diretório dos Índios: Artigo 6․ 2015. Disponível em: < http://www.nacaomestica.org/diretorio_ dos_indios.htm >. Acesso em: 12 nov. 2015.

ORLANDI, E. Análise de Discurso: Princípios e procedimentos. 12 ed. Pontes, Campinas, SP: 2015. 
. Formação ou capacitação? duas formas de ligar sociedade e conhecimento. In: FERREIRA, E.L.; ORLANDI, E. (org). Discurso sobre a inclusão. Niterói, Intertexto, 2014.

. As formas do silêncio: no movimento dos sentidos. 6 . Ed. Campinas: SP. Editora da Unicamp, 2007.

. História das ideias linguísticas: construção do saber metalinguístico e constituição da língua nacional. 3 ed. Campinas, SP: Vozes, 2001.

. Discurso, imaginário social e conhecimento. Em Aberto, Brasília, ano 14, n.61, jan./mar. 1994.

PAYER, M.O. Memória da língua: imigração e nacionalidade. São Paulo: Escuta, 2006.

. Memória da língua: imigração e nacionalidade. 1999. 186f. Tese (Doutorado em Linguística). Instituto de Estudos da Linguagem, Universidade Estadual de Campinas. IEL/ UNICAMP. Campinas, SP, 1999.

PECCHEUX, M. Semântica e discurso: uma crítica à afirmação do óbvio. Trad. E. Orlandi. 2 ed. Campinas SP: Editora da Unicamp, 1995.

PIRES, C.R.S. O uso da língua geral e sua restrição na América portuguesa. Espaço acadêmico, n.93, fev. 2009.

PROJETO Político Pedagógico (PPP). Escola Estadual 13 de Maio. Porto Esperidião, MT, 2016, 403p.

RODRIGUES, A.D. Sobre a contribuição linguística da Comissão Rondon. Anais da $56^{a}$ Reunião Anual da SBPC - Cuiabá, MT - Julho/2004. Disponível em: < http://www.sbpenet.org. br/livro/56ra/banco_conf_simp/textos/Aryonrodrigues.conf. htm >. Acesso em: 29 jun. 2016.

SERRANI-INFANTE, S. Diversidade e alteridade na enunciação em línguas próximas. Letras, Porto Alegre, n.14, p. 11-17, 1997. Disponível em: < https://periodicos.ufsm.br/letras/article/ view/11462/6929 >. Acesso em 14 jan. 2017.

SCHONS, C.R.. Escrita, efeito de memória e produção de sentidos. In: ; RÖSING, T.M.K. (org.). Questões de escrita. 2.ed. Passo Fundo. Ed. Universidade de Passo Fundo. 2011. 
SILVA S.A. Bolivianos em São Paulo: entre o sonho e a realidade. Estudos Avançados. V.20, n.57, São Paulo, mai.ago., 2006. Disponível em: < http://dx.doi.org/10.1590/S010340142006000200012 >. Acesso em: 16 dez. 2016.

STURZA, E.R. Das experiências e aprendizados do Programa Escolas Interculturais de Fronteira. Escolas Interculturais de Fronteira. Salto Para o Futuro. Ano XXIV, Boletim 1, p.23-28, maio de 2014.

ZOPPI-FONTANA, M. Identidades (in) formais: contradição, processos de designação e subjetivação na diferença. Organon 35, Rio Grande do Sul, v.17, n.35, p. 245-282, 2003.

\begin{abstract}
The teaching of languages in the border region: processes of subjectivation of the immigrant student

This study subscribes within the scope in the Linguistic Ideas History, articulated in the Discourse Analyzes of the line materialist, with the objective to understand the constitution of subjects and of the languages, by means of the memory of the traces of the language manifested in situations of Teachinglearning. We took a look at the policies of language, to the extent that we consider the national matter as a matter of state and we thought in its articulation with teaching. We note that the encounter with other(s) languages(s) leaves on the subject marks of subjectivity and, in the languages, the marks of the memory that constitute it.
\end{abstract}

Keywords: Language teaching. Border. Memory. Subjectivation. Public policies. 